American Journal of Applied Sciences 7 (6): 852-858, 2010

ISSN 1546-9239

(C) 2010 Science Publications

\title{
Eco-Efficient Product Design Using Theory of Inventive Problem Solving (TRIZ) Principles
}

\author{
Issac Lim Sing Sheng and Teoh Kok-Soo \\ Department of Mechanical Engineering, School of Engineering, \\ Monash University Sunway Campus, Sunway, Malaysia
}

\begin{abstract}
Problem statement: In recent years, much attention has been focused on the eco-efficiency of product development. The majority of environmental decisions are only made in the later stages of product development where not much modification can be done. To produce eco-efficient products, environmental decisions ought to be considered in the early stages of product development. With the demand of developing more eco-efficient products, designers are found to be lacking the appropriate design tools and guidelines. Approach: Products were designed to solve problems. Therefore, we suggest the usage of the 40 principles of TRIZ to generate eco-efficient product designs. The 40 principles of TRIZ is one of the fundamental tools of TRIZ. We studied the design features of different water filters, washing machines and power drills to correlate the elements of eco-efficiency and the principles of TRIZ. Results: From the case studies, it was shown that there is a correlation between eco-efficient elements and TRIZ principles in existing products. The information obtained from the product case studies alongside with the study of the individual TRIZ principles resulted in the formation of a new tool. This new tool was called the TRIZEE Design Tool. After that, literature review on the commonly practiced design methodologies were carried out. A new methodology termed TRIZEE Design Methodology was developed. New tools and existing tools were incorporated within this methodology. Conclusion: We proved that there is a correlation between eco-efficient elements and the 40 principles of TRIZ. Through this research, a new design methodology is also formed to that can be a guideline for designers.
\end{abstract}

Key words: Product design, eco-efficiency, TRIZ, TRIZEE

\section{INTRODUCTION}

In the pursuit of economic prosperity, the environment is left in the state of decline. With prosperous economies, the lifestyle of mankind has also elevated. More natural resources are used to sustain such lifestyles and even more irreversible damage is done on the environment. The consumption of energy, water and non renewable resources is increasing, on both a total and per capita basis (Rock and Angel, 2009). Shortages are ensuing in many parts of the world even in the present time. Such developments are not sustainable due to its lack of eco-efficiency. Every product impacts the environment throughout its lifecycle. In order to have a sustainable environment, more eco-efficient products should be designed. One of the main challenges for product designers is the lack of tools to incorporate environmental decisions (McAloone et al., 1998). This research aims to develop a design methodology for ecoefficient products using TRIZ principles.
Eco-efficiency elements: Eco-efficiency was originally defined by the World Business Council for Sustainable Development (WBCSD) back in 1992 before the Earth Summit in Rio de Janeiro. In exact definition, WBCSD states that eco-efficiency is reached by the delivery of competitively priced goods and services that satisfy human needs and bring quality of life, while progressively reducing ecological impacts and resource intensity. Eco-efficiency is categorized according to the seven elements. The eco-efficiency elements are reduction of material, energy and toxicity in goods and services. Other eco-efficient elements are increase in the usage of renewable resources, durability and service intensity of the product.

TRIZ principles: In the 1940s, a Russian inventor by the name of Genrikh Saulovich Altshuller researched for some generic rules that would explain creation of new, inventive, patentable ideas. After correlating

Corresponding Author: Issac Lim Sing Sheng, Department of Mechanical Engineering, School of Engineering, Monash University Sunway Campus, Sunway, Malaysia 
thousands of patterns, he discovered that all industries utilized the same underlying inventive principles. These principles could be generalized and universally applied. Therefore, Altshuller developed the TRIZ methodology which is the Russian acronym for Teoriya Resheniya Izobretatelskikh Zadatch meaning 'The theory of inventive problem solving'. Inventive problem solving can now be learnt and taught. The main TRIZ tool used in this research is the 40 principles of TRIZ (Technical Innovation Center, 2009).

\section{MATERIALS AND METHODS}

Design methodology: A general eco-efficient product design methodology has been developed. This methodology is further improved by gaining feedback information from the industry. Information and feedback are obtained through company interviews and product case studies.
In this research, the approach of applying Ecoefficiency elements and TRIZ principles are integrated with the proposed TRIZEE (TRIZ Eco-efficiency) Design Methodology.

TRIZEE design methodology: There are numerous product design methodologies being practiced in the industry. For this project to be relevant and effective in the general industry, the nature of the proposed TRIZEE Design Methodology functions as a complement and not as a substitute for existing design processes. The methodology is set up to complement general design processes. New design tools are developed in this project.

In general the design methodology consists of four main design phases which are problem origin, problem exploration, solution generation and evaluation. The flow chart in Fig. 1 displays the complete TRIZEE Design Methodology.

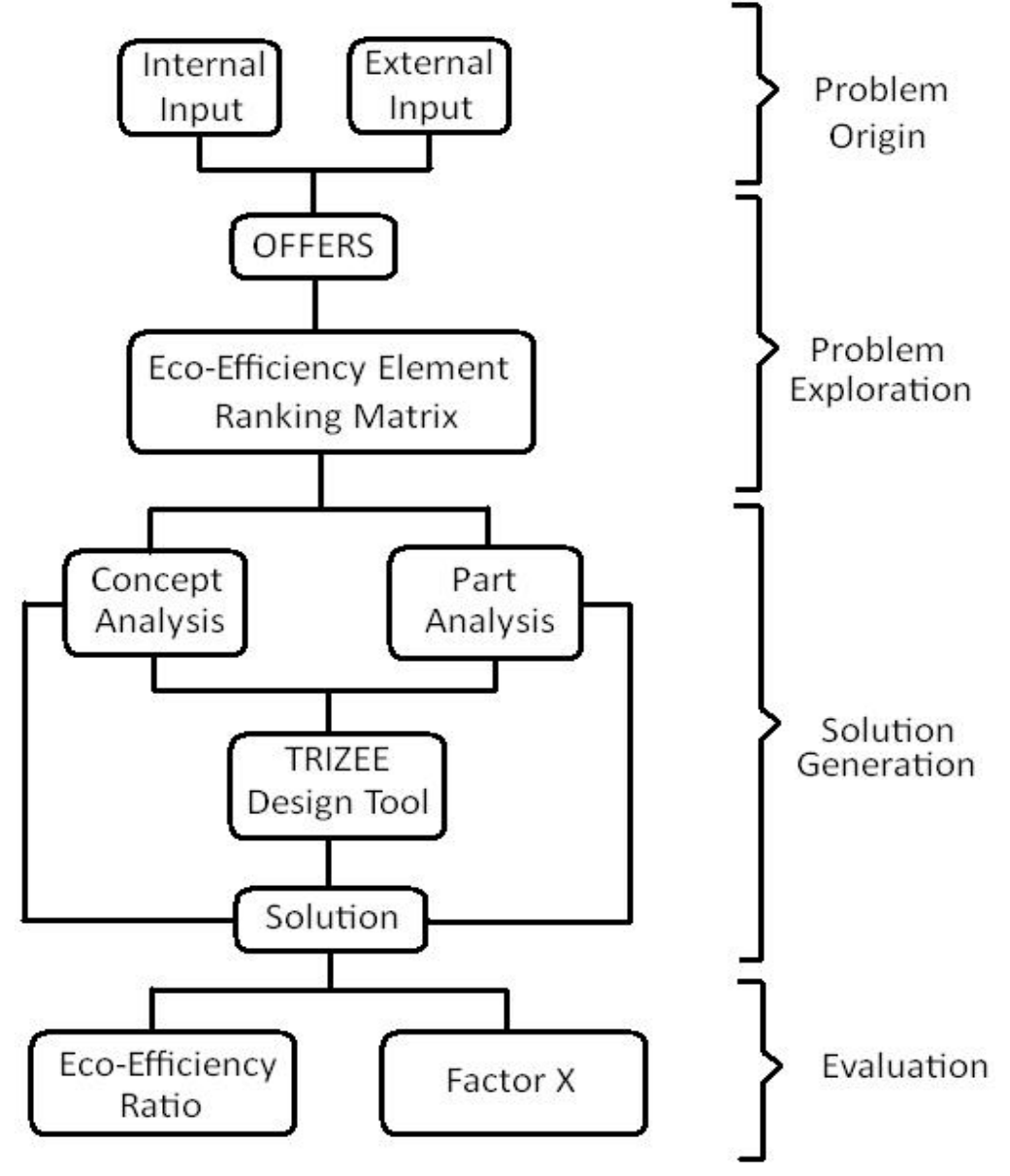

Fig. 1: TRIZEE design methodology 
Am. J. Applied Sci., 7 (6): 852-858, 2010

Table 1: Eco-efficiency element ranking matrix

\begin{tabular}{lllllllll}
\hline Eco-efficiency & & & & & & & & \\
Element & 1 & 2 & 3 & 4 & 5 & 6 & 7 & Total score \\
\hline 1 & - & & & & & & & \\
2 & & - & & & & & & \\
3 & & & - & & & & & \\
4 & & & & - & & & & \\
5 & & & & & - & & & \\
6 & & & & & & - & & \\
7 & & & & & & & - & \\
\hline
\end{tabular}

Table 2: TRIZEE design tool

\begin{tabular}{ll}
\hline Eco-efficiency element & TRIZ principles \\
\hline Material reduction & $1,4,5,6,7,8,9,13,14,16,17,18,23$, \\
& $26,28,29,30,31,34,35,36,37,40$ \\
Energy reduction & $1,5,6,7,9,10,12,13,14,16,17,18$, \\
& $19,20,23,25,26,28,29,31,38,39$ \\
Toxicity reduction & $2,9,10,11,13,16,18,21,22,23,24$, \\
& $30,38,39$ \\
Increase recyclability & $1,2,9,10,11,12,13,15,21,22,24,29$, \\
& $32,33,34,35,37$ \\
Increase resource sustainable & $3,8,18,25,28,36,37$ \\
Increase product durability & $7,9,10,11,14,39$ \\
Increase product service & $1,4,5,6,7,9,10,14,15,17,18,24,25$, \\
& $27,29,30,31,32,36,38,39$ \\
\hline
\end{tabular}

Problem origin: A design problem can be initiated internally or externally. The first is the internal input from the company itself. Internal inputs are driven by the company's own initiation to improve the ecoefficiency of its products. External inputs are factors that are beyond the influence of the company.

Problem exploration: According to Altshuller (1996), a problem ought to be termed as concise as possible.

To help explore the problem, an existing tool called OFFERS is used. The term OFFERS in an acronym of the different considerations evaluated while defining the problem. These considerations are objective, function, factors, effects, requirements and specifications (Field, 2006).

The type of eco-efficiency element that is to be improved depends on the capability of the design team. Through OFFERS, designers could identify the restrictions that will govern their design strategy.

To assist designers in selecting the suitable ecoefficiency requirement, a tool has been designed. It is termed the Eco-Efficiency Element Ranking Matrix. Information from the design objective, functions and factors will assist the usage of this matrix.

The eco-efficiency requirement ranking matrix consists of the product requirements on the horizontal as well as the vertical columns as shown in Table 1. For this project, the 7 eco-efficiency elements are the requirements for product design. A score of ' 1 ' ' is given if a particular requirement is more important than the compared requirement. If not, a ' 0 ' is given instead. The requirement with the highest total score will have the main priority in design considerations.

Solution generation: There are two strategies of generating solutions. One is through concept analysis and the other is through part analysis. Concept analysis is used to generate designs of a totally new product. The new concept generated is different from the trends seen in existing as well as previous models. Part analysis on the other hand is used for the improvement existing parts of a product. It is carried out through reverse engineering. Part analysis is most commonly practiced due to its shorter development period as compared to concept analysis.

The core of this methodology is the TRIZEE design tool. Compared to sustainable design practices, the TRIZEE design tool provides structured problem solving guideline in the integrated form of ecoefficiency elements and TRIZ principles.

After studying the definitions and applications of each of the 40 TRIZ principles, eco-efficiency elements were linked to the individual principles (Table 2). After determining which eco-efficiency element is required, solutions can be generated using the associated TRIZ principles as listed in the following TRIZEE Design Tool. Concept and part analysis is reiterated till the products meet the eco-efficient design specifications.

Evaluation: Evaluation of a designed product is done through the use of indicators. There are two indicators proposed for the TRIZEE design methodology which are the Eco-Efficiency Ratio and Factor X. These two indicators provide a quantitative evaluation of the level of eco-efficiency of products and were developed by WBCSD and Japan Environmental Management Association for Industry (JEMAI).

\section{Eco-efficiency ratio formula:}

$$
\text { Eco-efficiency Ratio }=\frac{\text { Product value }}{\text { Environmentalinfluence }}
$$

For the Eco-efficiency Ratio, the numerator is represented by the perceived value of the product. Environmental influence or impact represents the denominator for this indicator. A product's ecoefficiency is higher if the value of the product outweighs its environmental impact. 
The eco-efficiency formula brings together the two eco dimensions of economy and ecology to relate product value to environmental impact. Different companies use indicators with a slight difference of system boundaries. Companies such as NEC, Sony, Canon and Ricoh represent product value in terms of financial performance. Other companies by the likes of Matsushita, Panasonic, Mitsubishi, Hitachi, Fujitsu and Toshiba evaluates product feature instead of its financial aspect (Aoe et al., 2005). After analyzing the annual environmental report of Panasonic, Sanyo and Toshiba, it is concluded that there is commonly an emphasis on four common environmental aspects. These aspects in terms of eco-efficiency elements are the reduction of material, energy, toxicity and the increase of recyclability.

\section{Factor X formula:}

$$
\text { Factor } \mathrm{X}=\frac{\text { Eco-efficiencyof the new product }}{\text { Eco-efficiencyof the old product }}
$$

Factor $\mathrm{X}$ is the ratio of the eco-efficiency of the evaluated product over the previous or competing product (Nakaniwa, 2001). With Factor X, companies are able to gauge the quantitative advancement their product's eco-efficiency.

\section{RESULTS}

The product case studies were aimed to prove the correlation between eco-efficiency and TRIZ in current product designs. By proving this correlation through the case studies, the adaptability of TRIZEE design tool can be proven. Separate case studies on products were conducted for concept and part analysis. Water filter and washing machine are the types of products chosen for concept analysis. As for part analysis, electric impact drills were chosen as case study.
Concept analysis of water filters: There are numerous products that provide us with potable water. Six different water filters were chosen for study. They are the distiller, reverse osmosis, ultra violet radiation system, water ionizer, carbon and water filters.

Generally, the studied water filters can be grouped into three concepts. The first concept removes contamination, the second distills the water and the third inactivates microorganism. The water filter concepts, eco-efficiency elements and TRIZ principles are correlated in Table 3.

Concept analysis of washing machines: Current washing machine manufacturers in the market focus on precise motor control for energy efficiency and dynamic washing drum design for increased water agitation. However, a Japanese based home appliances manufacturer has successfully introduced three new concepts to its washing machine. Firstly, it has an option of cleaning using ozone instead of water. Another concept is its recycling of bathwater. Besides that, the drum is positioned higher and at an angle. Ecoefficiency elements and TRIZ principles are then related to the individual concepts. Table 4 showed the description of the correlated eco-efficiency elements and TRIZ principles for the different concepts of existing washing machines.

Part analysis: This type of product is chosen because it is commonly used both by the industry as well as the consumer market. Two different brands were selected for case study. Brand B is of a European based company and was manufactured locally in Malaysia. Brand $\mathrm{S}$ is produced by an Asian Original Equipment Manufacturer (OEM). It is manufactured and imported from the same country as the OEM. Both of the drills have impact mode and were similar in their power rating of $500 \mathrm{~W}$. The drills were reverse engineered through a series of dismantling processes.

Table 3: Correlation between water filter concepts, eco-efficiency element and TRIZ principle

\begin{tabular}{|c|c|c|}
\hline Concept & Eco-efficiency element & TRIZ principle \\
\hline \multirow[t]{2}{*}{ Filters } & Energy reduction: & \#31 porous material \\
\hline & Electricity is not needed. & Ceramic and carbon filters are porous. \\
\hline \multirow[t]{4}{*}{ Distillation } & Toxicity reduction: & \#29 hydraulic \\
\hline & No chemicals needed. & Pressure is applied to induce reverse osmosis. \\
\hline & Material reduction: & \#30 flexible membrane \\
\hline & $\begin{array}{l}\text { Filter mechanism is replaced by flexible } \\
\text { membrane which is made of lesser material. } \\
\text { Product service: }\end{array}$ & Thin layer of membrane acts as filter for extremely small particles. \\
\hline \multirow{4}{*}{ Inactivate microorganisms } & Effectively kills all microorganism while & \#18 mechanical vibration \\
\hline & preserving the water minerals. & UV light is a high frequency wave. \\
\hline & & $\# 38$ accelerated oxygen \\
\hline & & Sliver ions are impregnated into the carbon filters. \\
\hline
\end{tabular}


Am. J. Applied Sci., 7 (6): 852-858, 2010

Table 4: Correlation between washing machine concepts, eco-efficiency element and TRIZ principle

Concept
Ozone:
injected in the air is converted to ozone and
from delicate clothing.

Material reduction:
Ozone is used instead of water to disinfect
and deodorize.

TRIZ principle

\#38 Use strong oxidizers

Transition from one level of oxidation to the next higher level.

Ozone is a strong oxidant which can be

Toxicity reduction: generated from normal air.

It is able to kill odor-causing bacteria

although it is non toxic.

Product service:

Reduction of cycle time from 30-20 min.

Possible to wash more delicate fabrics that

are vulnerable to heat.

\section{Recycled water:}

Bathwater is cleaned and recycled for use in laundry. The water is cleaned by infusing ozone in micro bubble form.

Higher and angled drum:

Material reduction:

Bathwater as well as water used in rinse cycle is cleaned using ozone and reused for washing. Less fresh water is used for washing.

\section{Product service:}

The height of the washing drum is designed to be as high as an average kitchen counter.

The drum is also tilted instead of the conventional front or top loading orientation.
Easy to reach without straining while loading or unloading the drum. Stress on knees, elbows and backs will be reduced.
\#22 Convert harm into benefit

Waste water contains causes pollution. Using

ozone to disinfect, waste water is converted into water that is fit for washing laundry. \#4 Asymmetry

Conventional washing machines are designed to be symmetrical in shape.

This washing machine employs the principle of asymmetry as the washing drum is tilted upwards in an angle.

Table 5: Correlation between the design of power drill parts, eco-efficiency elements and TRIZ principles

Description of part
Muantity of screws:
sections. One less screw is used at the handle
the Bosch drill as compared to the Starke drill.
Types of screws:
There is a single type of screw used for the
Bosch drill. This is opposed to the variety of
three screws sizes used for the Starke drill.

\section{Interior structure:}

Ribs are placed within the motor and chuck section. For the Starke drill, internal ribs are only designed in the horizontal plane. Additional ribs in the vertical plane are designed for Bosch drill.

\section{Power cord inlet:}

The power cord is connected to the drill through the bottom handle. For the Starke drill, the power cord enters perpendicularly to the bottom of the handle. As for the Bosch drill, it connects to the handle at an angle.

Number of fins:

There are a total of 39 fins for the Bosch fan as oppose to the 32 fins for the Starke drill.

Eco-efficiency element

The Bosch drill needs one less screw.

It may seem insignificant but as the drill is manufactured by the tens of thousands, a considerable amount of material saving can be achieved. Savings in raw material usage translates directly to monetary savings as well. Enhance recyclability:

It is faster to assemble as well as disassemble components that are attached by a single type of screw. It eliminates the need of another tool. Hence, decreasing time and effort in separating the product components.

\section{Increase service intensity:}

The motor as well as the chuck fits firmer on the horizontal and vertical ribs. Hence, the internal components will not shift and cause additional vibration. Ultimately, torque will be delivered efficiently from the motor to the drill bit.

\section{Increase service intensity:}

If the power cord is connected at an angle to the handle, there will be less obstruction to the user's wrist and arm. This promotes better handling of the drill during operation.

\section{Increase service intensity:}

Prevents the motor from overheating. More fins in the fan will increase air flow and ultimately will dissipate heat in a shorter period of time.

TRIZ principle

\#3 local quality

Screws are only placed in critical vibration areas such as the motor and chuck sections. Less screw is used at the bottom of the Bosch drill handle where vibration is minimal relative to the other parts.

\section{\#33 homogeneity}

Identical screws are used to at the different parts of the product.

\#17 transition into a new dimension The internal structure has ribs that are positioned both in the horizontal as well as the vertical axis.

\#14 spheroidility

A linear design for the power cord inlet is changed into a curved path.

\#25 self service

The torque generated to drive the chuck is also used to rotate the fan. 
Each of the drill was brand new before its functions were tested. Information such as the performance and ease of use were recorded. Next, the drill is dismantled to its separate parts. Not all of parts can be separated individually. Some were tightly fixed since product assembly. Each dismantling step was photographed. The parts later named and quantified. Both of the action and tool needed to dismantle the parts were recorded as well in the dismantling list. Once dismantling has been completed, the body of material is listed. The feature of the parts such as quantity, weight and dimension was catalogued. This information from both drills was compared to each other.

For parts of similar function, the differences in terms of design features were noted. This information from both drills was compared to each other. The power drill design features, eco-efficient elements and TRIZ principles are then correlated in Table 5.

\section{DISCUSSION}

Products come in a variety of concepts and parts. From the case study of concept analysis, it is learnt that there are multiple products that are designed to achieve the same function of producing potable water. The water filters are considerably different in terms of concept.

Products with a similar concept were studied in part analysis. For products with similar concept like the electric power drills, there are only minor differences in the design of its parts and components. Each differing concept and part has its own eco-efficiency advantage over the other. All of the principles used in designing the studied products were found in the list of TRIZ principles.

The product case study has reached its aim, which is to prove that there is a correlation between ecoefficient elements and TRIZ principles in existing product designs. Therefore, it is possible to use the TRIZEE Design Tool directly to generate solutions for eco-efficient products.

\section{CONCLUSION}

The contribution of this project is twofold. First, the benefits eco-efficiency to both the economy and ecology can be shared by the industry, consumers and the environment. Next, designers and engineers are introduced to the powerful set of TRIZ inventive principles to improve the thinking process behind the generation of design concepts and solutions. Ecoefficient product design is more reliable and predictable through the works of this project.

For every eco-efficiency element featured in the product case study, the usage of a TRIZ principle can be identified. This indicates the existence of a link between eco-efficiency elements and TRIZ principles. Therefore, the TRIZEE design tool can be used directly in guiding designers to select the possible TRIZ principles needed to increase eco-efficiency elements of the designed product. The simplicity of the proposed TRIZEE design methodology enables also it to be assimilated into concept as well as part design processes.

Further works includes the modification of the TRIZEE Design Tool as more product case studies are carried out. The TRIZEE design Methodology will also be tested in actual product development projects through industrial collaboration. Finally, more new design tools will be developed using the other tools of TRIZ.

\section{REFERENCES}

Altshuller, G., 1996. And Suddenly The Inventor Appeared TRIZ, the Theory of Inventive Problem Solving. 2nd Edn., Technical Innovation Centre, Inc., Worcester, ISBN: 10: 0964074028, pp: 196.

Aoe, T., S. Kurihara, O. Namikawa, T. Takahashi and C. Nakaniwa, 2005. Publication of the ecoefficiency Handbook in 2004 Eco-efficiency Project in Japan. Proceeding of the 4th International Symposium on Environmentally Conscious Design and Inverse Manufacturing, Dec. 12-14, IEEE Xplore Press, USA., pp: 764-765. DOI: 10.1109/ECODIM.2005.1619344

Field, B.W., 2006. Introduction to Engineering Design. 1st Edn., Monash University, Australia, ISBN: 0732622867, pp: 316.

McAloone, T.C., T.A. Bhamra and S. Evans, 1998. Success in environmentally conscious design: How is it achieved and maintained? Proceeding of the IEEE International Symposium on Electronics and the Environment, May 4-6, IEEE Xplore Press, Oak Brook, IL., USA., pp: 171-175. DOI: 10.1109/ISEE.1998.675052 
Nakaniwa, C., 2001. Development of eco-efficiency indicators regarding products. Japan Environmental Management Association for Industry. http://www.jemai.or.jp/JEMAI_DYNAMIC/data/c urrent/detailobj-2001-attachment.pdf

Rock, M.T. and D.P. Angel, 2009. Grow first, clean up later? Industrial Transformation in East Asia. Taylor and Francis Group. http://www.environmentmagazine.org/Archives/Ba ck\%20Issues/May\%202007/Rock-abstract.html
Technical Innovation Center, 2009. Altshuller. TRIZ. http://www.triz.org/triz/altshuller.shtml 